\title{
Spatial Determinants of Land Prices: Does Auckland's Metropolitan Urban Limit Have an Effect?
}

\author{
Arthur Grimes • Yun Liang
}

Received: 30 January 2008 / Accepted: 11 June 2008 /

Published online: 4 July 2008

(C) The Author(s) 2008

\begin{abstract}
Land prices within monocentric cities typically decline from the centre to the urban periphery. More complex patterns are observed in polycentric and coastal cities; discrete jumps in value can occur across zoning boundaries. Auckland (New Zealand) is a polycentric, coastal city with clear-cut zoning boundaries. Information on land price patterns within the city is important to understand the nature of development and the effects of regulation in causing discrete land valuation changes. One key zoning regulation in Auckland is a growth boundary, termed the metropolitan urban limit (MUL). We examine whether the existence of this growth limit affects land prices. We do so in the context of a model of all Auckland land values over a twelve year period, finding a strong zoning boundary effect on land prices. Specifically, after controlling for other factors, we find that land just inside the MUL boundary is valued (per hectare) at approximately 10 times land that is just outside the boundary.
\end{abstract}

Keywords Boundary effects · Growth limits · Land value gradients ·

Zoning restrictions

\section{Introduction}

Land values indicate the market value that people ascribe to specific places. These values are affected by demand factors, such as views, amenities, proximity to employment and availability of infrastructure. One reason that land value is a particularly useful indicator of the value of infrastructure and amenities is that land is a fixed factor. Other factors (labour and capital) migrate in response to new

\footnotetext{
A. Grimes $(\bowtie) \cdot$ Y. Liang

Motu Economic \& Public Policy Research, PO Box 24390, Wellington, New Zealand e-mail: arthur.grimes@motu.org.nz

Y. Liang

e-mail: yun.liang@motu.org.nz
} 
opportunities and services, so bidding up the price of the fixed factor in the area in which those opportunities and services arise. ${ }^{1}$

In studying such effects, one must also understand the nature of land supply, including regulatory restrictions on land use. In urban areas, growth limits and other zoning restrictions fulfill a regulatory role in governing the nature of a city's development. In this study, we examine the impact of a particular set of growth limits: Auckland's Metropolitan Urban Limits (MUL). The MULs are set as part of the Auckland Regional Policy Statement (ARPS), a planning document with a statutory basis. ${ }^{2}$ The MULs are used "to define the boundary of the urban area with the rural part of the region." 3 We analyse whether the MUL in Auckland affects land prices in the city. Specifically we model land prices across the greater Auckland region and test whether land prices exhibit a boundary effect at the limits prescribed by the MUL boundary. If the MUL constitutes a binding constraint on land supply for the city, land just inside the boundary will be valued more highly than land just outside.

Growth limits are designed to affect the location and nature of urban expansion. In order to judge the impacts of say an infrastructure project or new social amenity, the nature of zoning restrictions must be understood. For instance, a new transport route may not result in new development if zoning restrictions prevent location of new activities near the route, whereas considerable development may take place in the absence of such restrictions.

Whether growth limits or other forms of zoning restrictions (e.g. residential-only zones) have a material effect on land values, at either a localized scale or at a citywide scale, depends on a number of factors. First, a growth limit may not be binding. If a city's current and prospective expansion is well within the growth limit, no citywide effect should be experienced and little local effect will be apparent. Second, a growth limit may be circumvented (as reported by Pendall (1999) for some cases in the USA). Third, a growth limit may be binding in certain directions but not others. In these cases, the growth limit may have a localized boundary effect on land values where the constraint binds, but will not necessarily have a major effect on overall city-wide prices. Fourth, growth limits may be varied over time in response to economic and population developments.

Growth limits are used as planning tools in many countries. A theoretical rationale that supports the use of growth boundaries arises where traffic congestion is unpriced, so that cities sprawl in an inefficient manner. In the absence of congestion pricing, a growth limit may be a second-best policy to deal with congestion and sprawl (Kanemoto 1977; Arnott 1979; Pines and Sadka 1985). Analyses supporting this approach tend to be based on a monocentric city model. In many cases, however, cities are polycentric. Anas and Rhee $(2006,2007)$ show that in such cities, urban growth boundaries are not generally second-best policy instruments and may have seriously negative welfare consequences. Indeed, in cities

\footnotetext{
${ }^{1}$ Roback (1982), Haughwout (2002), McMillen and McDonald (2004).

${ }^{2}$ For the full ARPS see: http://www.arc.govt.nz/plans/regional-policy-and-plans/auckland-regional-policystatement/auckland-regional-policy-statement_home.cfm (accessed 23 May 2008).

${ }^{3}$ Auckland Regional Growth Forum (1999), p. 5.
} 
with cross-commuting and faced with congestion, they show that it may be optimal for the city to increase its sprawl.

Even where urban growth boundaries may be an optimal or second-best response to unpriced externalities, their operation may cause negative welfare consequences. Knaap and Hopkins (2001) contrast an optimal inventory management approach to urban growth boundaries with actual management approaches. Typically, revisions to urban growth boundaries are made at discrete points of time (e.g. every 10 years). Knaap and Hopkins show that this approach is inflexible in the face of unanticipated economic and demographic developments. Instead, boundaries need to be revised on a continuous basis reacting to the available supply and price of vacant land. In particular, boundaries require expansion once the price of land within the boundary relative to an external benchmark rises past some critical threshold. Their analysis places the issue of discrete boundary effects for land values at centre-stage in analyzing the effects and efficiency of a growth limit.

Considerable evidence exists in the United States that urban growth boundaries can have major effects on patterns and dynamics of new housing supply and on land prices (Malpezzi 1996; Ryan et al 2004; Pendall et al 2006). In summarizing the results of a number of studies from California (Dowall 1979; Dowall and Landis 1982; Landis 1986), where growth boundaries have been in use since the 1960s, Anthony (2003) reports a consistent finding that growth limits result in higher housing prices. Downs (1992) found that in San Diego County, the median sale price of existing houses rose by $54 \%$ within three years of the imposition of a growth boundary. Katz and Rosen (1987), Schwartz et al (1981) and Zorn et al (1986) have found similar effects. More recently, a significant body of work by Glaeser, Gyourko and associates ${ }^{4}$ finds that land use regulation, including growth controls, has had major effects on city house prices in the USA.

Literature on empirical effects of growth limits in New Zealand generally, and specifically of the MUL in Auckland, is sparse. Figure 1 maps the Auckland Region (and its seven constituent Territorial Authorities) showing the MUL. The area within the main part of the MUL includes the northern parts of Manukau City and Papakura District, Auckland City, the eastern part of Waitakere City and most of North Shore City. Rodney District has an area on its east coast (adjacent to, and stretching along, the Whangaparoa Peninsula) that lies within a separate area of the MUL. Grimes et al. (2007) found that new residential building in Auckland is prevalent just inside the MUL boundaries, contrasting with a lack of similar activity on the outward side of the boundary. This provides prima facie evidence that the boundary has been effective in containing residential development in and around Auckland. ${ }^{5}$

A study by the Auckland Regional Growth Forum (1999) [ARGF], conducted shortly after formal adoption of the MUL in 1998, examined the historical use and impact of growth limits in Auckland. It noted that MULs have been used for the past

\footnotetext{
${ }^{4}$ Glaeser and Gyourko (2002, 2003), Glaeser et al. (2005), Glaser and Ward (2006), Gyourko et al. (2006).

${ }^{5}$ DTZ (2007) summarise legal and planning details regarding the MUL and other zoning controls. The regulatory authority (Auckland Regional Council) adopts a non-permissive approach to any urban activity (even a school) that may be sought in areas outside the MUL. Penalties for non-compliance (e.g. building a structure contrary to restrictions) can include fines and removal of the structure.
} 


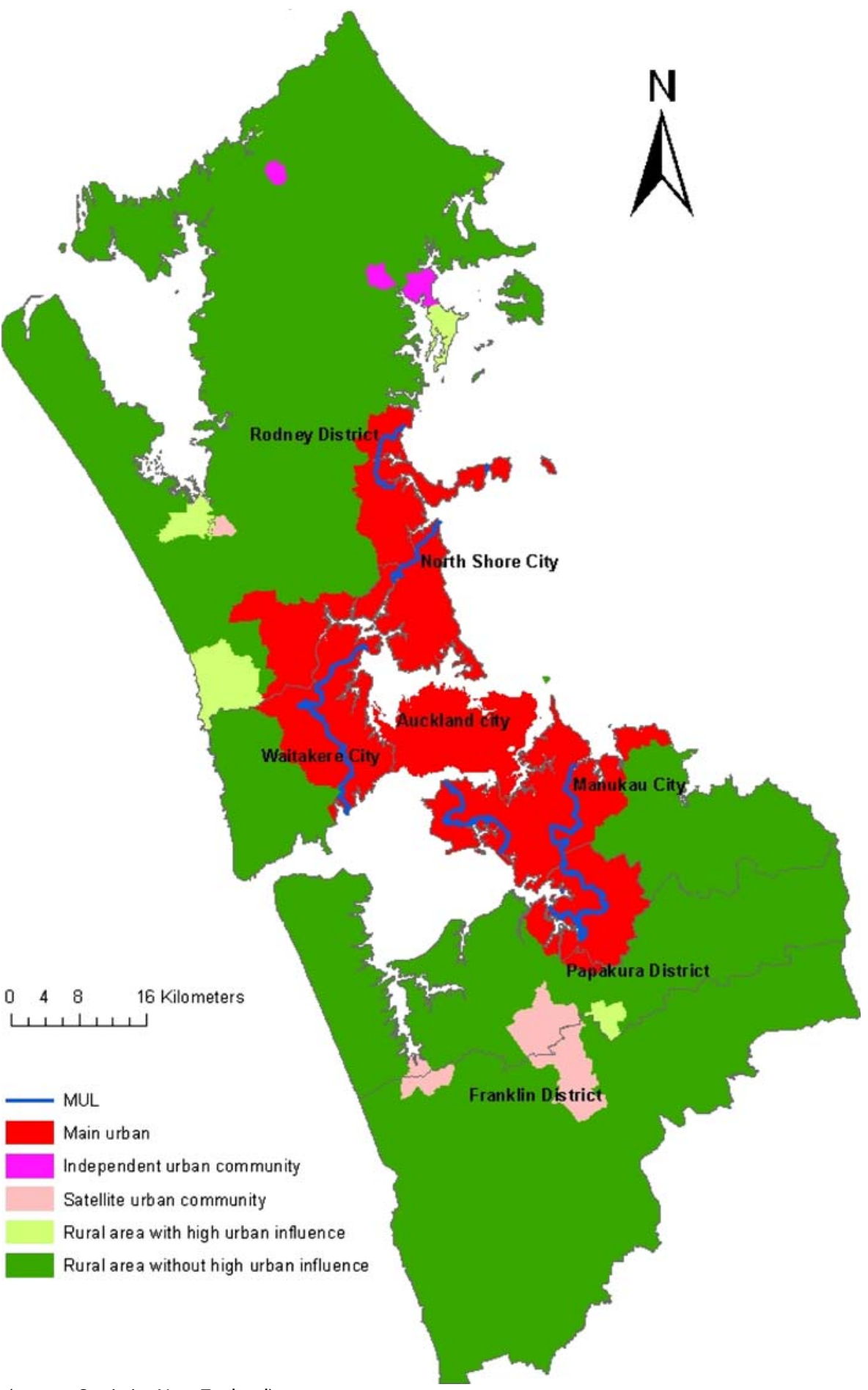

(source: Statistics New Zealand)

Fig. 1 Auckland: MUL, territorial authorities and urban/rural profile for 1992 (source: Statistics New Zealand) 
fifty years in Auckland, so their use under the 1998 Regional Growth Strategy is not new. In earlier years, the prime motivation for their use was to avoid inefficient and expensive provision of urban infrastructure but "in more recent times the emphasis has switched to protection of the environment in the area outside the MUL" (ARGF, p. 4).

The study referred to some unpublished modeling work on the impact of the MUL on land prices that found land just inside the boundary worth more than land just outside. ${ }^{6}$ This result is consistent with the MUL constraining effective land supply for urban purposes, causing a step change in the return to land inside the boundary relative to the (mainly agricultural) return from land just outside the boundary. In interpreting this result, the ARGF noted that reasons for this result could include topography, ${ }^{7}$ greater provision of infrastructure (e.g. sewerage) for land inside the $\mathrm{MUL}^{8}$ and high amenity value for land just inside the MUL due to residents pricing in easy access to the countryside. The report suggested that this latter factor "could push up land prices near the MUL relative to other parts of the urban area that don't have such good access to the countryside" (p. 3).

Several more years of data are now available with which to evaluate the effect of the MUL on Auckland land prices. The current study conducts an analysis of these effects across a number of years. ${ }^{9}$ It does so within a model of wider Auckland land values. This model assists in understanding not only the MUL impact, but also the impact on land values of distances from key nodes (including the CBD), distance from the coast, differential effects across local authorities and types of land (e.g. rural versus other). In some estimates, we control for the impact of social variables (population density, incomes and levels of relative deprivation) which in turn may reflect amenity effects referred to by the ARGF. By controlling for a wide range of factors that may otherwise affect land values, we are able to identify the impacts of the MUL boundaries on land prices around Auckland.

The paper proceeds as follows. "Methodology" describes our methodology, followed by a brief description of our data ( "Data"). Results are presented in "Results", using a number of specifications and estimation techniques. Conclusions are contained in "Conclusions".

\section{Methodology}

The emphasis of our study is on the effects of the metropolitan urban limits (MUL) on Auckland land prices. We examine the boundary effects of the MUL within a model of land prices across Auckland. Specifically, we model the per hectare land

\footnotetext{
${ }^{6}$ The study refers to commissioned unpublished econometric work conducted by Steven Bourassa (then of University of Auckland).

${ }^{7}$ However in many parts of the MUL boundary it is not clear that land on the outside of the boundary is topographically less attractive for residential purposes than land inside the boundary.

${ }^{8}$ If infrastructure services were priced fully through land taxes (rates) or user charges this factor should not affect the respective land values since owners of land inside the MUL will face higher rates and/or user charges than owners of land outside the MUL. In practice, charges are differentiated in this manner.

${ }^{9}$ Bourassa et al. (2006) found that the price of aesthetic externalities varies over time in Auckland.
} 
value of each meshblock in the greater Auckland region, comprising the seven territorial local authorities (TAs): Rodney, North Shore, Waitakere, Auckland City, Manukau, Papakura and Franklin. A meshblock is the smallest area used to collect and present statistics by Statistics New Zealand. Meshblocks in rural areas generally have a population of around 60 people; in urban areas a meshblock is roughly the size of a city block and contains approximately 110 people (source: Statistics New Zealand).

We denote the per hectare land value in meshblock $j$ at time $t$ as $\mathrm{LMB}_{\mathrm{jt}}$. For all our estimates, we deflate $\mathrm{LMB}_{j t}$ by $\mathrm{LWH}_{t}$, the average land price in the two other major cities (Wellington and Hamilton) in New Zealand's North Island. In our baseline model, the relative land value $\left[\ln \left(\mathrm{LMB}_{j t} / \mathrm{LWH}_{t}\right)\right]$ is modeled as a function of distance from the coast, distance from the $\mathrm{CBD}$, distance from other key nodes, TA effects, impacts of being inside or outside the MUL, plus a 'rural' variable. An extended model also includes the influence of social variables (income, relative deprivation and population density). These controls are included to ensure that our results for each year are obtained after abstracting from any national and regional influences on local land values.

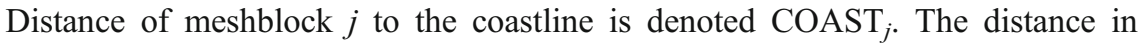
kilometres is measured from the geographic centroid of the meshblock to the nearest point on the coastline.

Distances from the CBD and other nodes are measured as the distance of the centroid of meshblock $j$ from the centroid of the Auckland CBD (taken to be the Britomart transport centre) and other chosen "peak points" throughout the region. The choice of non-CBD peak points recognises that Auckland is a polycentric city; hence land values are a function of multiple activity nodes throughout the region. To the north and west of the urban area, the following nodes are adopted: Wellsford, Leigh, Mahurangi, Omaha, Warkworth, Snells Beach, Orewa, Helensville, Parakai, Muriwai, Kumeu and Piha. To the south of the urban area, Pukekohe, Waiuku and Bombay are chosen. Within the urban area, in addition to the CBD, nodes are: Takapuna, Newmarket, Pakuranga, Mangere Airport, Otahuhu, Manukau City, Manurewa and Papakura. The choice of nodes is made on the basis of two approaches. First, we include those areas beyond the metropolitan area defined by Statistics New Zealand in its Urban/Rural Profile for 1992 (the start of our sample) as 'independent urban community', 'satellite urban community' and 'rural area with high urban influence'. Figure 1 indicates each of these areas. Second, we identify localized high-priced areas in 1991 within the MUL that reflect obvious activity nodes (such as the airport) and/or historic town centres now part of the urban area.

The distance of meshblock $j$ from node $k$ is denoted DIST $_{j k}$ subject to imposition of a minimum distance of $0.25 \mathrm{~km}$, even where the meshblock is the node. The same minimum is adopted for $\mathrm{COAST}_{j}$. The reasons for adopting the $0.25 \mathrm{~km}$ minimum are twofold. First, each meshblock has positive area, so zero distance is not a complete characterization of the distance of a meshblock from the local node (or coast) even where that meshblock forms the local node. The chosen minimum $(250 \mathrm{~m})$ is a short walking distance so appears reasonable as a characterization of a meshblock from its own centroid.

Second, we model the effects of distance using a non-linear function that includes a logarithmic transformation; thus zero is a non-eligible distance value. For each 
relevant distance, we model the natural logarithm $(\mathrm{ln})$ of $\mathrm{LMB}_{j t}$ as a function of both $\mathrm{DIST}_{j k}$ and $\ln \left(\mathrm{DIST}_{j k}\right)$ plus a constant. This enables freely estimated functions that can vary non-linearly with distance. We cap distance from the coast and distance from all nodes other than the CBD at $5 \mathrm{~km}$ (i.e. the effect beyond $5 \mathrm{~km}$ is assumed identical to the effect at $5 \mathrm{~km}$ ) to reflect the idea that a local node has only a local effect on land values. No distance cap is placed on the effect of distance from the $\mathrm{CBD} .{ }^{10}$ We expect each of the overall distance effects to be negative over the relevant range. We supplement the distance variables with a dummy variable (RURAL92) for meshblocks categorised as 'rural area without high urban influence'.

MUL impacts are captured by use of dummy variables. We construct six variables, DMUL1 $1_{j}, \ldots$, DMUL6 $_{j}$, (where each dummy variable is either 0 or 1 for meshblock $j$ ), that start from the inner urban area moving outwards. Meshblocks that lie wholly inside the (1998) MUL boundaries have either DMUL $1_{j}=1$ or $\mathrm{DMUL}_{j}=$ 1. The distinction between the two is that meshblocks contiguous with the MUL (or contiguous with a meshblock that has the MUL running through it) have DMUL2 ${ }_{j}=$ 1 and DMUL $1_{j}=0$; all other 'inner' meshblocks have DMUL $1_{j}=1$ and DMUL $2_{j}=0$. Meshblocks that have the MUL running through them are called 'cross meshblocks' and have DMUL $3_{j}=1$. Meshblocks that lie just outside the MUL have DMUL4 ${ }_{j}=1$; meshblocks with DMUL5 $5_{j}=1$ lie immediately outside the DMUL4 meshblocks; and all other (outer) meshblocks have DMUL6 $\sigma_{j}=1$.

The reason for including a layer of meshblocks $\left(\right.$ DMUL $\left._{j}=1\right)$ just outside those with DMUL $_{j}=1$ is twofold. First, there is a possibility at all times that the MUL may be shifted outwards. The stated policy is that any such shift should be contiguous with the existing metropolitan area, so there is an option value for meshblock land just outside the existing MUL. This may affect both neighbouring meshblocks and those a little further out but to differing degrees. Second, it is possible that undeveloped land contiguous with built-up areas is less attractive in an amenity sense than is land slightly further distant. Additionally, zoning rules relating to lot size, building type, allowable activities, etc may apply differentially to areas that are slightly further distant from the metropolitan edge.

We hypothesise that land just outside the MUL (i.e. with DMUL $_{j}=1$ ) will be valued less than land inside the growth boundary $\left(\mathrm{DMUL}_{j}=1\right.$ or DMUL $2_{j}=1$ ), with cross meshblocks $\left(\mathrm{DMUL}_{j}=1\right.$ ) being valued in between. We hypothesise further that in early years, land just inside the MUL may be partially rural in character and therefore valued at a lower rate than inner-most land (after controlling for distance), but as the metropolitan area has expanded, this DMUL2 land will no longer bear a discount. We let the data indicate the relevant patterns for each year. In estimation, we omit DMUL1 $1_{j}$ from the equation, so all results are expressed relative to the innermost (main urban) meshblocks.

The baseline equation includes a set of dummy variables representing the different TAs in the region: Rodney $\left(\mathrm{TA}_{j}\right)$, North Shore $\left(\mathrm{TA} 5_{j}\right)$, Waitakere $\left(\mathrm{TA}_{j}\right)$, Manukau $\left(\mathrm{TA} 8_{j}\right)$, Papakura $\left(\mathrm{TA} 9_{j}\right)$ and Franklin $\left(\mathrm{TA}_{10} 0_{j}\right.$ ); Auckland City is excluded, so coefficients indicate any systematic variation in land values by TA relative to

\footnotetext{
${ }^{10}$ All major results of the paper are robust to different specifications of the local and coastal distance caps including use of unlimited distance specifications.
} 
Auckland City, after controlling for other effects. Such differences may relate to different social amenities, infrasatructure and/or property taxes (rates).

The resulting baseline equation is presented as 1 :

$$
\begin{aligned}
\ln \left(L M B_{j t} / L W H_{t}\right) & =\sum_{k}\left\{\alpha_{k}+\beta_{k} \times D I S T_{j k}+\gamma_{k} \times \ln \left(D I S T_{j k}\right)\right\} \\
& +\delta_{1} \times C O A S T_{j}+\delta_{2} \times \ln \left(C O A S T_{j}\right) \\
& +\varepsilon_{2} \times D M U L 2_{j}+\varepsilon_{3} \times D M U L 3_{j}+\varepsilon_{4} \times D M U L 4_{j}+\varepsilon_{5} \times D M U L 5_{j}+\varepsilon_{6} \times D M U L 6_{j} \\
& +\varphi_{4} \times T A 4_{j}+\varphi_{5} \times T A 5_{j}+\varphi_{6} \times T A 6_{j}+\varphi_{8} \times T A 8_{j}+\varphi_{9} \times T A 9_{j}+\varphi_{10} \times T A 10_{j} \\
& +\eta_{1} \times R U R A L 92_{j}+\mu_{j t}
\end{aligned}
$$

where $\mu_{\mathrm{jt}}$ is a residual term (discussed below) and other variables are defined in Table 1.

All variables included in the baseline model with the exception of RURAL92 are distance or administrative variables; all are treated as exogenous. The baseline specification recognizes that land values are driven by individuals' location decisions

\begin{tabular}{|c|c|}
\hline Variables & Definition \\
\hline $\begin{array}{l}\text { LMB }_{j t} \\
\text { LWH }_{t} \\
\text { DIST }_{j k} \\
\text { COAST }_{j} \\
\text { DMUL1 }_{j} \\
\text { DMUL2 }_{j} \\
\text { DMUL3 }_{j} \\
\text { DMUL4 }_{j} \\
\text { DMUL5 }_{j} \\
\text { DMUL6 }_{j} \\
\text { TA4 }_{j} \\
\text { TA5 }_{j} \\
\text { TA6 }_{j} \\
\text { TA7 }_{j} \\
\text { TA8 }_{j} \\
\text { TA9 }_{j} \\
\text { TA10 }_{j} \\
\text { RURAL9 }_{j} \\
\text { MEDINC1991 }_{j} \\
\text { POPDENS199 }_{j} \\
\text { NZDEP1991 }_{j}\end{array}$ & $\begin{array}{l}\text { Land value per hectare of meshblock } j \text { in year } t^{\mathrm{a}} \\
\text { Land value per hectare in Hamilton and Wellington cities }{ }^{\mathrm{a}} \\
\text { Distance of meshblock } j \text { from node } k^{\mathrm{b}, \mathrm{c}} \\
\text { Distance of meshblock } j \text { from the coast } \\
\text { Binary variable }=1 \text { if meshblock } j \text { lies inside DMUL2 area }(=0 \text { otherwise })^{\mathrm{c}} \\
\text { Binary variable }=1 \text { if meshblock } j \text { just inside MUL }(=0 \text { otherwise })^{\mathrm{c}} \\
\text { Binary variable }=1 \text { if MUL runs through meshblock } j(=0 \text { otherwise })^{\mathrm{c}} \\
\text { Binary variable }=1 \text { if meshblock } j \text { just outside MUL }(=0 \text { otherwise })^{\mathrm{c}} \\
\text { Binary variable }=1 \text { if meshblock } j \text { just beyond DMUL4 area }(=0 \text { otherwise })^{\mathrm{c}} \\
\text { Binary variable }=1 \text { if meshblock } j \text { outside DMUL5 area }(=0 \text { otherwise })^{\mathrm{c}} \\
\text { Binary variable }=1 \text { if meshblock } j \text { in Rodney TA }(=0 \text { otherwise })^{\mathrm{c}} \\
\text { Binary variable }=1 \text { if meshblock } j \text { in North Shore TA }(=0 \text { otherwise })^{\mathrm{c}} \\
\text { Binary variable }=1 \text { if meshblock } j \text { in Waitakere TA }(=0 \text { otherwise })^{\mathrm{c}} \\
\text { Binary variable }=1 \text { if meshblock } j \text { in Auckland City TA }(=0 \text { otherwise })^{\mathrm{c}} \\
\text { Binary variable }=1 \text { if meshblock } j \text { in Manukau TA }(=0 \text { otherwise })^{\mathrm{c}} \\
\text { Binary variable }=1 \text { if meshblock } j \text { in Papakura TA }(=0 \text { otherwise })^{\mathrm{c}} \\
\text { Binary variable }=1 \text { if meshblock } j \text { in Franklin TA }(=0 \text { otherwise })^{\mathrm{c}} \\
\text { Binary variable }=1 \text { if meshblock } j \text { defined as rural }(=0 \text { otherwise })^{\mathrm{d}} \\
\text { Median income of meshblock } j \text { in } 1991^{\mathrm{e}} \\
\text { Population density of meshblock } j \text { in } 1991^{\mathrm{e}} \\
\text { NZ Deprivation score for meshblock } j \text { in } 1991^{\mathrm{f}}\end{array}$ \\
\hline
\end{tabular}
relating to each of these variables. In some circumstances, location decisions (and hence land values) are also affected by other agents' location decisions. For instance, the neighbourhood effects literature (Haurin et al. 2003) indicates that people will bid

Table 1 Variable definitions (and data sources)

\footnotetext{
${ }^{\text {a }}$ Source: Quotable Value New Zealand

${ }^{\mathrm{b}} k=0$ represents the CBD (Britomart); $k>0$ represent the other 23 nodes; $0.25 \mathrm{~km} \leq \mathrm{DIST}_{j k}$ for $k=0$; $0.25 \mathrm{~km} \leq \mathrm{DIST}_{j k} \leq 5 \mathrm{~km}$ for $k>0 ; 0.25 \mathrm{~km} \leq \mathrm{COAST}_{j} \leq 5 \mathrm{~km}$ for all $j$

${ }^{c}$ Source: GIS calculations

${ }^{\mathrm{d}}$ Source: Statistics New Zealand Urban/Rural Profile 1992

e Source: Statistics New Zealand 1991 census

${ }^{\mathrm{f}}$ Source: Crampton et al. (2000), based on Statistics New Zealand 1991 census
} 
more highly for land located near wealthier and/or higher status individuals. Population density may also affect the value placed on land, both directly (through increasing the number of people bidding for a particular area of land) and indirectly (e.g. through increased provision of social amenities catering for the denser population).

Omission of controls for these effects could bias the coefficient estimates in the baseline model. However each of these 'social' control variables also reflects the physical and administrative features (e.g. population density is greater around the coast reflecting the benefits of living in a coastal location). They may be endogenous (e.g. population density may be affected by land values). Inclusion of their effect could therefore bias the coefficient estimates in the opposite direction.

To test the robustness of our results, we estimate a second, extended, model. This model includes all variables in the baseline model with the addition of three variables measuring: the median income in the meshblock in 1991 (MEDINC1991 ${ }_{j}$ ), the meshblock's population density in 1991 (POPDENS1991 ${ }_{j}$ ) and a summary measure (NZDEP1991 $)_{j}$ ) of the meshblock's relative deprivation status in 1991 (Crampton et al. 2000). We expect the first two variables to have positive coefficients and the third to be negative. These coefficient signs are consistent both with high income households locating near areas with positive amenity values and with the availability of amenities being positively correlated with population density. ${ }^{11}$ Each of the social variables is measured in 1991, the year before the start of our sample, to minimize endogeneity problems.

The residual term, $\mu_{j t}$, may exhibit a number of non-classical properties. First, it may be heteroskedastic; we therefore use heteroskedasticity-adjusted standard errors (all reported significance tests are based on these standard errors).

Second, we have the potential for spatial autocorrelation (Anselin 1988; Samarshinghe and Sharp 2007). Spatial autocorrelation is present when the error in one meshblock is (positively or negatively) related to the error in a spatially proximate meshblock. Spatial proximity here is measured by distance between meshblock centroids. Our use of distance functions from 24 nodes (including the CBD) and from the coast is designed to lessen the problems of spatial autocorrelation. Initially, therefore, we estimate the baseline and extended models by OLS and test the residuals for spatial autocorrelation using Moran's $I$ statistic. $^{12}$

If spatial autocorrelation is indicated by Moran's $I$, we test the robustness of our results by estimating three further models using both the baseline and extended specifications. First, we estimate the models supplemented by 'area unit' effects by adding 350 dummy variables for area units (which are akin to 'suburbs') to our models. Second, we estimate a spatial lag model in which values in a meshblock are modeled as a function of underlying determinants and of values in nearby

\footnotetext{
${ }^{11}$ In keeping with these priors, meshblock land values in 1992 are positively correlated with population density (correlation coefficient of 0.59 ) and with median income $(0.18)$ and negatively correlated with the deprivation index (-0.08). In addition, median income is negatively correlated with deprivation $(-0.61)$. Population density is positively correlated with deprivation $(0.26)$ and negatively with income $(-0.12)$. We include the three social variables in our extended equation solely as extra control variables and do not interpret the coefficients in a structural sense.

${ }^{12}$ Moran's $I$ indicates the correlation of residuals across different spatial bands (Moran 1950).
} 
meshblocks. Third, we estimate a spatial error model in which the residual for a meshblock is modeled as a function of the residuals in nearby meshblocks. Spatial lag and spatial error models in general can be summarized as follows:

$$
\begin{gathered}
\boldsymbol{Y}=\rho \boldsymbol{W} \boldsymbol{Y}+\boldsymbol{X} \beta+\mu \\
\mu=\lambda \boldsymbol{W} \boldsymbol{\mu}+\varepsilon \\
\varepsilon \sim N(0, \Omega)
\end{gathered}
$$

where $\boldsymbol{Y}$, the dependent variable (in our case, real meshblock land values) is an $\mathrm{nx} 1$ vector, $\mathbf{X}$ is an nxk matrix of $k$ explanatory variables as per our baseline and extended models with associated parameters $\beta, \mathbf{W}$ is a specified row standardized spatial weight matrix (in our case with weights given by distances between meshblock centroids up to $20 \mathrm{~km}), \rho$ measures the extent to which one observation is spatially dependent on its neighbours, ${ }^{13}$ and $\lambda$ measures the extent to which an error of one observation is related to errors of neighbouring observations. ${ }^{14}$ We report the robustness of our results to each of these specifications.

\section{Data}

All distance data, TA boundaries and coastal boundaries have been derived using GIS techniques, employing linear distances. RURAL92 data and definitions of other urban and rural types are obtained from Statistics New Zealand (urban/rural profile for 1992). The Statistics New Zealand 1991 census is the source of data for MEDINC1991, POPDENS1991 and (indirectly) for NZDEP1991. MUL boundary data, obtained from Auckland Regional Council, refers to the MUL boundaries set in 1998. There have been four minor boundary changes at the end of our sample (between 2002 and 2005); their effects may not be reflected in rateable values (our land value data source) up to 2004. We therefore use the 1998 boundaries throughout our analysis. ${ }^{15}$

Land value data are obtained from Grimes and Liang (2007). Land values (i.e. rateable values for land used for property tax purposes) are obtained from Quotable Value New Zealand for meshblocks in each of the seven TAs. Revaluations take place mostly on a three-yearly rotational basis. We have interpolated these data to annual frequency using vacant section sale price data for each TA. The interpolation

\footnotetext{
${ }^{13}$ For instance, $\rho>0$ may arise where values in a meshblock are affected by the value of an amenity located in a neighbouring meshblock.

${ }^{14}$ For instance, $\lambda>0$ may arise where there are spatially correlated omitted variables or spatially correlated errors in measurement of regression variables.

${ }^{15}$ These boundaries are certainly appropriate for our 1998 and 2001 estimates. It is possible that our 2003/ 2004 estimates are affected by the subsequent slight MUL changes; our expectation is that any such effect will be minor given the small nature of the changes. While the MUL did not exist formally prior to 1998, its 1998 boundaries to a large extent mirrored pre-1998 zoning boundaries (ARGF 1999) so, on this basis, the 1998 boundaries represent appropriate measures for the earlier years' MUL.
} 
Table 2 Summary by DMUL status of real per hectare land value

\begin{tabular}{llllllrl}
\hline & \multicolumn{7}{l}{ Year } \\
\cline { 2 - 5 } & 1992 & 1995 & 1998 & 2001 & 2003 & Obs. & \% change: 1992-2003 \\
\hline DMUL1 & 3.933 & 3.581 & 4.708 & 5.164 & 6.268 & 6524 & 59 \\
DMUL2 & 1.782 & 1.797 & 2.344 & 2.182 & 2.520 & 281 & 41 \\
DMUL3 & 0.923 & 0.919 & 1.268 & 1.210 & 1.413 & 183 & 53 \\
DMUL4 & 0.125 & 0.134 & 0.161 & 0.170 & 0.216 & 92 & 73 \\
DMUL5 & 0.132 & 0.130 & 0.156 & 0.154 & 0.183 & 77 & 39 \\
DMUL6 & 0.434 & 0.425 & 0.568 & 0.566 & 0.595 & 883 & 37 \\
Total & 3.325 & 3.039 & 3.997 & 4.359 & 5.276 & 8,040 & 59 \\
\hline
\end{tabular}

Real per hectare land value is average land value per hectare in the defined area expressed relative to average per hectare land values in Hamilton and Wellington for the same year. All measures in the table use a consistent sample of meshblocks throughout the sample period. DMUL1 land is within the core metropolitan area, DMUL2 land is within the growth boundary but contiguous with it (or with a cross meshblock), DMUL3 denotes cross meshblocks (which have the MUL running through them), DMUL4 land is outside the MUL boundary but is contiguous with it (or with a cross meshblock), DMUL5 land lies just outside DMUL4 land, and DMUL6 covers all other land beyond DMUL5

is undertaken so that we can compare land values across the region for any given year (given that land is valued in different years within a triennial cycle in different TAs). We have full data from 1992 through to 2003 for every TA and through to 2004 for all TAs other than Papakura and Franklin. Since the underlying values are obtained triennially, we report on our data, and estimate our equations, for every third year: 1992, 1995, 1998, 2001 and 2003. ${ }^{16}$

Prior to estimation, we examine some summary statistics for land values in the context of our MUL dummy variable (DMUL) definitions. Table 2 summarises real per hectare land values for each of the DMUL categories and for the greater Auckland region. All values have been deflated by the average of Hamilton and Wellington land values; hence the figures represent per hectare values relative to average land values in these two cities.

A number of factors are apparent from Table 2. First, land prices decrease monotonically from DMUL1 land to DMUL5 land for every year. The average value for DMUL6 land, which includes some high priced nodes plus coastal as well as rural land is, on average, higher than other land beyond the MUL boundary but less than land inside the boundary. Second, all categories of land within the Auckland region have increased in value over the sample period relative to land in Hamilton and Wellington. Third, real rates of increase in land values have varied across the region according to DMUL category. The highest increase (73\%) is for DMUL4 land, possibly indicating an increased option value for land just beyond the MUL, that in turn reflects a perceived increasing probability of an outward shift in the MUL as real Auckland land values escalate.

Table 3 splits the MUL boundary into four separate segments that we label: Rodney, North Shore, Waitakere and Manukau/Papakura. These four segments

\footnotetext{
${ }^{16}$ We use 2003 as our final year since we have data for all seven TAs in 2003. For each year we have approximately 8,000 meshblock observations; there are slightly fewer observations for 1992 owing to lesser data quality in that year that necessitated greater data cleansing early in the sample.
} 
Table 3 Ratio of DMUL2:DMUL4 land value (per hectare) by MUL segment

\begin{tabular}{|c|c|c|c|c|c|}
\hline & \multicolumn{5}{|l|}{ Year } \\
\hline & 1992 & 1995 & 1998 & 2001 & 2003 \\
\hline Rodney & 22.609 & 24.146 & 22.995 & 19.353 & 17.836 \\
\hline North Shore & 16.390 & 17.034 & 17.680 & 15.591 & 16.964 \\
\hline Waitakere & 9.041 & 11.467 & 13.177 & 12.791 & 12.343 \\
\hline Manukau/Papakura & 15.766 & 15.091 & 15.660 & 14.035 & 12.301 \\
\hline Total & 14.438 & 14.589 & 15.580 & 14.004 & 13.054 \\
\hline
\end{tabular}

All measures in the table use a consistent sample of meshblocks throughout the sample period

reflect four distinct parts of the MUL boundaries as depicted in Fig. 1 (the small segment of land to the west of Manukau is excluded as a separate segment but is included in the total figure). The table reports, for each segment and for each year, the ratio of the mean per hectare land value within DMUL2 relative to the mean per hectare land value within DMUL4.

The total ratio stayed fairly constant throughout the sample with land just inside the MUL being 13-16 times as valuable (per hectare) as land just outside the MUL boundary. Patterns differed across segments, however, with a declining ratio in Rodney and Manukau/Papakura and an initially increasing ratio in Waitakere. These raw figures indicate a prima facie case for a boundary effect around the MUL for each segment, and they are consistent with the findings of Grimes et al. (2007) regarding the location of new residential building consents in relation to the MUL boundaries. Nevertheless, the raw figures presented here do not control for other effects (e.g. proximity to the coast, distance from the CBD or social and physical amenity values). Our estimates in the next section are designed to estimate the boundary effects more precisely after controlling for such effects.

\section{Results}

We present results both for our baseline model, Eq. 1, and for the extended model that adds the three social variables, MEDINC1991, POPDENS1991 and NZDEP1991 (as defined in Table 1). Our key focus is a comparison of the estimated coefficients on DMUL2 $\left(\varepsilon_{2}\right)$ and DMUL4 $\left(\varepsilon_{4}\right)$ over each of our sample years. To be confident that our model explains spatial urban land values satisfactorily, we expect $\varepsilon_{2} \approx 0$, at least for later years when the MUL is likely to have been more binding. If that is the case, and if $\varepsilon_{2}>\varepsilon_{4}$, we can infer that a boundary effect exists with land just inside the MUL being valued more highly than that just outside the MUL after controlling for other factors. (In this situation, we also expect that $\varepsilon_{2}>\varepsilon_{3}>\varepsilon_{4}$, implying that cross meshblocks are valued partially as lying inside, and partially outside, the MUL.)

Results from estimating the baseline model as separate cross-sections for each of 1992, 1995, 1998, 2001 and 2003, using OLS, are presented in Table 4. Meshblocks from all seven TAs are included in each cross-section. We present all coefficients 
Table 4 Baseline model: OLS results

\begin{tabular}{|c|c|c|c|c|c|}
\hline \multirow{2}{*}{$\begin{array}{l}\text { Baseline model: } 7 \text { TAs } \\
\text { Explanatory variables }\end{array}$} & \multicolumn{5}{|c|}{ Dependent variable is $\ln (\mathrm{LMB} / \mathrm{LWH})$} \\
\hline & 1992 & 1995 & 1998 & 2001 & 2003 \\
\hline DMUL2 & $-0.295 * * *$ & $-0.187 * * *$ & $-0.113 * *$ & -0.069 & -0.030 \\
\hline DMUL3 & $-1.362 * * *$ & $-1.129 * * *$ & $-1.028 * * *$ & $-0.922 * * *$ & $-0.817 * * *$ \\
\hline DMUL4 & $-2.667 * * *$ & $-2.642 * * *$ & $-2.682 * * *$ & $-2.624 * * *$ & $-2.491 * * *$ \\
\hline DMUL5 & $-2.466 * * *$ & $-2.336 * * *$ & $-2.418 * * *$ & $-2.454 * * *$ & $-2.302 * * *$ \\
\hline DMUL6 & $-2.231 * * *$ & $-2.064 * * *$ & $-2.169 * * *$ & $-2.208 * * *$ & $-2.042 * * *$ \\
\hline TA4 & $-0.784 * * *$ & $-0.230 * *$ & $-0.369 * * *$ & $-0.432 * * *$ & $-0.606 * * *$ \\
\hline TA5 & $0.115^{* * *}$ & $0.323 * * *$ & 0.042 & $-0.307 * * *$ & $-0.235^{* * *}$ \\
\hline TA6 & $-0.438 * * *$ & $-0.097 * * *$ & $-0.285 * * *$ & $-0.532 * * *$ & $-0.505 * * *$ \\
\hline TA8 & 0.069 & $0.507 * * *$ & $0.297 * * *$ & 0.078 & $0.109 * *$ \\
\hline TA9 & $-0.291 *$ & -0.148 & -0.084 & $-0.505 * * *$ & $-0.813 * * *$ \\
\hline TA10 & 0.078 & $0.456 * * *$ & 0.024 & $-0.214^{*}$ & $-0.284 * * *$ \\
\hline RURAL92 & $-1.034 * * *$ & $-1.245 * * *$ & $-1.222 * * *$ & $-1.202 * * *$ & $-1.256 * * *$ \\
\hline COAST & -0.003 & 0.004 & -0.014 & 0.005 & -0.003 \\
\hline $\ln (\mathrm{COAST})$ & $-0.103 * * *$ & $-0.105 * * *$ & $-0.087 * * *$ & $-0.101 * * *$ & $-0.094 * * *$ \\
\hline CBD & $-0.041 * * *$ & $-0.040 * * *$ & $-0.035 * * *$ & $-0.032 * * *$ & $-0.030 * * *$ \\
\hline $\ln (\mathrm{CBD})$ & $0.103 * *$ & 0.032 & $-0.077^{*}$ & $-0.131 * * *$ & $-0.203 * * *$ \\
\hline Observations & 7,716 & 8,005 & 8,019 & 8,059 & 8,051 \\
\hline$R^{2}$ & 0.729 & 0.729 & 0.768 & 0.783 & 0.804 \\
\hline
\end{tabular}

In addition, an overall equation constant plus constant, linear and logarithmic terms relating to 23 other nodes are included in the equation, but not reported for clarity

$* * * p<0.01, * * p<0.05, * p<0.1$

other than those pertaining to the non-CBD nodes. ${ }^{17}$ We have also estimated the same model for five TAs (excluding Papakura and Franklin) through to 2004. The results are very similar to the seven TA case, so we present the results solely for the seven TA specification.

\section{Baseline Model: Non-MUL Terms}

Coefficients on the distance functions for both COAST and CBD are such that there is a negative effect of both variables over their relevant ranges. ${ }^{18}$ This occurs even where one of the linear or logarithmic coefficients is positive. To demonstrate this, the impact of distance from the CBD on land values for each year is plotted in Fig. 2.

The impact of distance from the CBD on real land values in Auckland has changed virtually monotonically from 1992 to 2003. In 2003, the impacts of distance from the $\mathrm{CBD}$ at $0.25,5,25$ and $50 \mathrm{~km}$ were $1.315,0.621,0.247$ and 0.102 respectively. Thus land within the CBD was valued at just over twice the rate of land $5 \mathrm{~km}$ distant, ${ }^{19}$ five times the rate of land $25 \mathrm{~km}$ distant, and almost thirteen times the rate of land $50 \mathrm{~km}$ distant. In 1992, by contrast, land values rose slightly over the first $3 \mathrm{~km}$, with ratios of CBD land value to land at 25 and $50 \mathrm{~km}$ being 1.7 and 4.4

\footnotetext{
${ }^{17}$ Distance functions for the non-CBD nodes are almost all negative and significant, as hypothesised.

${ }^{18}$ Other than a slight non-monotonicity for the CBD at short distances in early years, as discussed below.

${ }^{19}$ I.e. $=1.315 / 0.621=2.12$.
} 


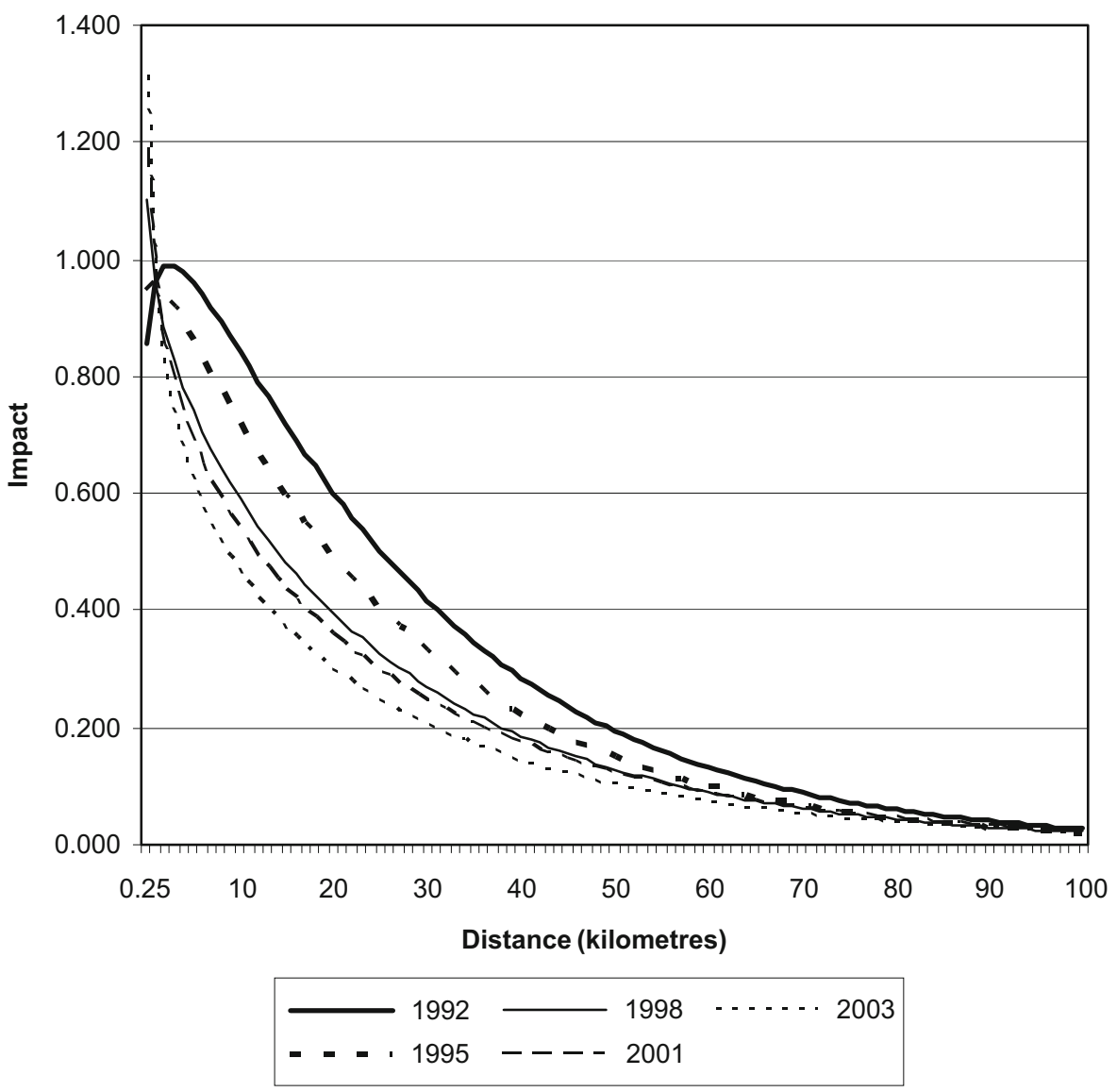

Fig. 2 Impact of distance from $\mathrm{CBD}$ on real land values - baseline model

respectively. Land value has therefore become more concentrated in the area close to the CBD, consistent with increasing agglomeration effects based on the CBD.

Figure 3 graphs the impact of distance from the coast on land values. Unlike the CBD distance effect, the effect of distance from the coast on the real value of land around Auckland has been remarkably stable over time. Furthermore, the (minor) changes have not been consistently in one direction; the 2003 effect is very close to that of 1992. Overall, a coastal location has commanded a premium over locations more distant from the coast over the whole period.

Of the other non-CBD variables, the coefficient on RURAL92 indicates that rural land is consistently cheaper than urban land even after accounting for distance and other effects. The TA dummies show that Auckland City is slightly more expensive than most other TAs, especially in later years. ${ }^{20}$ The $R^{2}$ statistic increases throughout the period from 0.729 in 1992 and 1995 to 0.804 in 2003. Overall, the high

\footnotetext{
${ }^{20}$ Rodney, Waitakere and Papakura are consistently the three 'cheapest' TAs after controlling for other influences. We do not speculate on the reasons behind the respective TA coefficients since they reflect a range of infrastructure, amenity, taxation and other factors.
} 


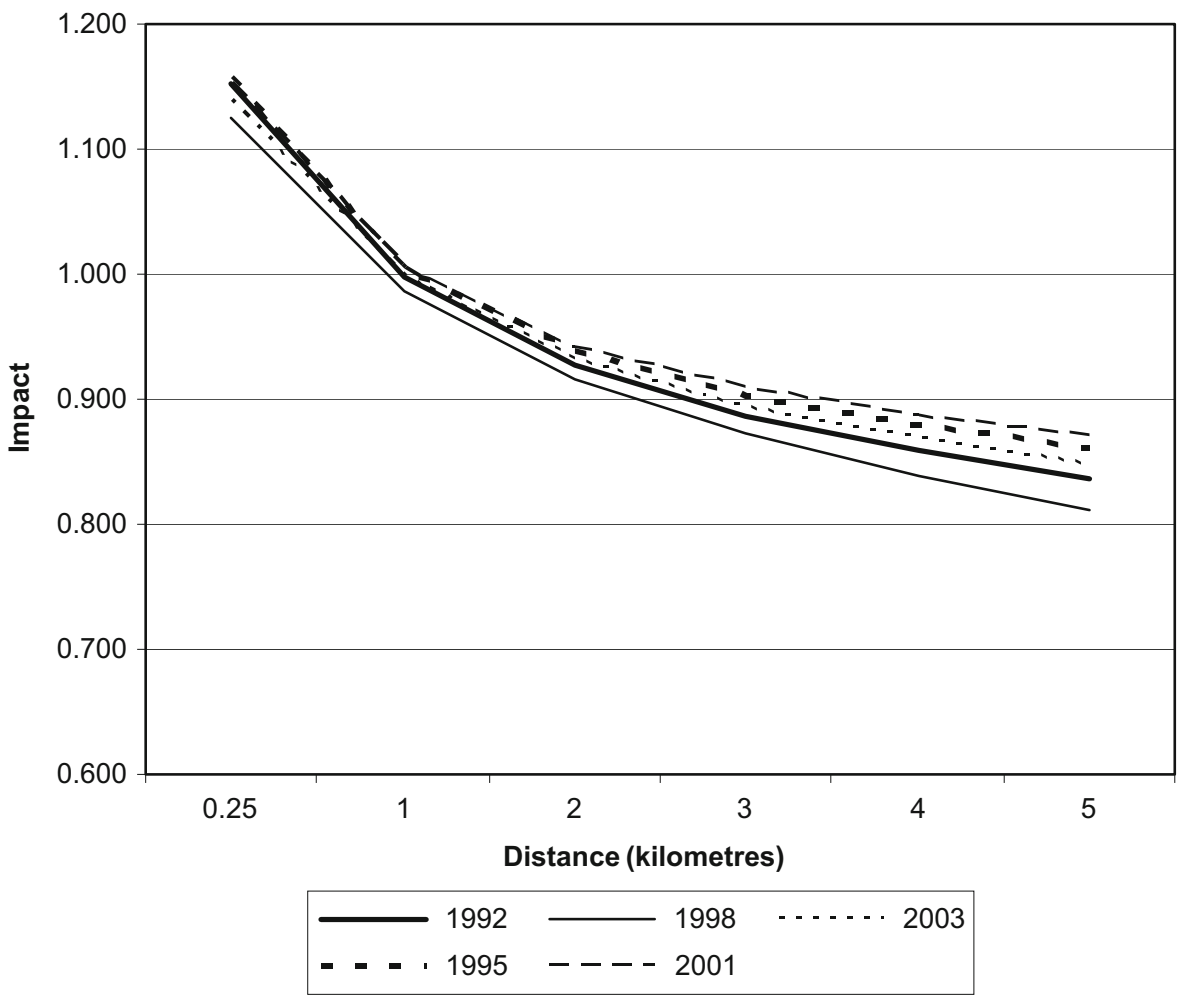

Fig. 3 Impact of distance from coast on real land values - baseline model

explanatory power and the sensible coefficients on each of the non-MUL terms give confidence that the MUL boundary effects are estimated within the context of a suitable model for urban and peri-urban land values.

\section{Baseline Model: MUL Boundary Effects}

In interpreting the MUL boundary effect, we first examine the behaviour of prices just within the MUL boundary. If the broader model is suitable for modeling land values across the region, we would expect that prices just within the MUL boundary will not be significantly different from those well within the boundary once distance and other controls have been accounted for. The exception would be if there were still major holdings of vacant land within this area.

Meshblocks in this area have DMUL2 $=1$. The coefficient on this term for the baseline equation in Table 4 is not significantly different from zero in either 2001 or 2003 implying that in later years the overall model fits the value of land situated just inside the MUL boundary as well as for land that is closer to the CBD. In prior years, this land is slightly under-priced relative to the overall model, with the degree of under-pricing increasing as the sample goes backwards. This finding is in keeping with the hypothesis that a greater portion of this land was rural earlier in the period. 
Overall, the DMUL2 coefficients imply that the model is valuing land close to the MUL boundary in an appropriate manner.

Land situated just outside the MUL boundary has a sharply decreased price compared with land situated just inside the MUL even with the inclusion of distance and other controls. In 1992, the difference between the coefficients on DMUL2 and DMUL4 was 2.372; since then the difference in coefficients has varied in a tight range between 2.455 and 2.569. Noting that the dependent variable in Eq. 1 is logarithmic, these coefficients indicate that land just inside the MUL boundary is around 12 times more expensive per hectare than is land situated just outside the MUL. $^{21}$

If this figure is caused by an MUL boundary effect, we would expect the cross meshblocks (DMUL3 =1) to reflect the partial effect of the MUL, as indeed occurs. Each of the DMUL3 coefficients is significantly negative. Consistent with the declining coefficient on DMUL2, the coefficient on DMUL3 has declined over time suggesting that much of the land in these cross meshblocks is now being developed or being priced for future development.

\section{Extended Model}

Results from estimating the extended model as separate cross-sections for each of 1992, 1995, 1998, 2001 and 2003, using OLS, are presented in Table 5. Meshblocks from all seven TAs are included in each cross-section; again we present all coefficients other than those pertaining to the non-CBD nodes. ${ }^{22}$

The distance effects are very similar to those in the baseline model, with land values becoming more concentrated towards the city centre over time. In 2003 the ratios of land values within the CBD relative to those 5,25 and $50 \mathrm{~km}$ distant are calculated at 2.5, 5.9 and 12.0 respectively. This compares with ratios of 1.0, 1.7 and 3.4 respectively in 1992. As in the baseline model, coastal effects have remained broadly constant over time. Rural and TA effects are similar to the baseline model.

The three social variables are all highly significant with the expected signs. Meshblocks with high population density and high median incomes are valued more highly than other meshblocks, while more deprived areas are associated with low land values. As discussed earlier, the direction of causality in these relationships could run both ways.

Very similar patterns are observed for each of the MUL variables as in the baseline model. The coefficient on DMUL2 (i.e. on meshblocks just inside the MUL boundary) declines monotonically throughout the sample as does the coefficient on the cross meshblocks (DMUL3). The difference between the coefficients on DMUL2 and DMUL4 rises between 1992 and 1998, and stays between 2.25 and 2.35 over 1998-2003. In 2003, land just inside the MUL is valued at 9.5 times that just outside the MUL.

\footnotetext{
${ }^{21}$ I.e. $\exp (2.5)=12.18$.

${ }^{22}$ One or more of the social variables is not available for some meshblocks, so the number of observations falls slightly relative to the baseline model. We have estimated the extended model for five TAs through to 2004. Again, the results are very similar so we confine our discussion to the seven TA estimates.
} 
Table 5 Extended model: OLS results

\begin{tabular}{|c|c|c|c|c|c|}
\hline \multirow{2}{*}{$\begin{array}{l}\text { Extended model: } 7 \text { TAs } \\
\text { Explanatory variables }\end{array}$} & \multicolumn{5}{|c|}{ Dependent variable is $\ln (\mathrm{LMB} / \mathrm{LWH})$} \\
\hline & 1992 & 1995 & 1998 & 2001 & 2003 \\
\hline DMUL2 & $-0.168 * * *$ & $-0.109 * *$ & -0.041 & -0.032 & -0.002 \\
\hline DMUL3 & $-1.037 * * *$ & $-0.892 * * *$ & $-0.792 * * *$ & $-0.780 * * *$ & $-0.680 * * *$ \\
\hline DMUL4 & $-2.235^{* * *}$ & $-2.263 * * *$ & $-2.311 * * *$ & $-2.380 * * *$ & $-2.255^{* * *}$ \\
\hline DMUL5 & $-2.038 * * *$ & $-1.970 * * *$ & $-2.046^{* * *}$ & $-2.191 * * *$ & $-2.051 * * *$ \\
\hline DMUL6 & $-1.698 * * *$ & $-1.607 * * *$ & $-1.737 * * *$ & $-1.886 * * *$ & $-1.747 * * *$ \\
\hline TA4 & $-0.778 * * *$ & $-0.269 * * *$ & $-0.393 * * *$ & $-0.449 * * *$ & $-0.629 * * *$ \\
\hline TA5 & $-0.066^{* *}$ & $0.132 * * *$ & $-0.121 * * *$ & $-0.471 * * *$ & $-0.382 * * *$ \\
\hline TA6 & $-0.352 * * *$ & -0.023 & $-0.226^{* * *}$ & $-0.492 * * *$ & $-0.467 * * *$ \\
\hline TA8 & $-0.191 * * *$ & $0.239 * * *$ & 0.065 & $-0.132 * * *$ & $-0.078^{*}$ \\
\hline TA9 & $-0.470 * * *$ & $-0.340 * * *$ & $-0.247 * *$ & $-0.678 * * *$ & $-0.968 * * *$ \\
\hline TA10 & -0.083 & $0.255^{* *}$ & -0.142 & $-0.360 * * *$ & $-0.419 * * *$ \\
\hline RURAL92 & $-1.134 * * *$ & $-1.285 * * *$ & $-1.254 * * *$ & $-1.257 * * *$ & $-1.293 * * *$ \\
\hline COAST & 0.013 & 0.010 & -0.008 & -0.001 & -0.010 \\
\hline $\ln (\mathrm{COAST})$ & $-0.145^{* * *}$ & $-0.131 * * *$ & $-0.115 * * *$ & $-0.110 * * *$ & $-0.101 * * *$ \\
\hline CBD & $-0.029 * * *$ & $-0.027 * * *$ & $-0.024^{* * *}$ & $-0.021 * * *$ & $-0.020 * * *$ \\
\hline $\ln (\mathrm{CBD})$ & 0.036 & -0.055 & $-0.131 * * *$ & $-0.214 * * *$ & $-0.276^{* * *}$ \\
\hline NZDEP1991 & $-0.090 * * *$ & $-0.094 * * *$ & $-0.080 * * *$ & $-0.070 * * *$ & $-0.063 * * *$ \\
\hline POPDENS1991 & $0.029 * * *$ & $0.027 * * *$ & $0.025 * * *$ & $0.018 * * *$ & $0.017 * * *$ \\
\hline MEDINC1991 & $0.015 * * *$ & $0.015 * * *$ & $0.014 * * *$ & $0.014 * * *$ & $0.013 * * *$ \\
\hline Observations & 7,586 & 7,859 & 7,868 & 7,898 & 7,890 \\
\hline$R^{2}$ & 0.808 & 0.810 & 0.832 & 0.832 & 0.845 \\
\hline
\end{tabular}

In addition, an overall equation constant plus constant, linear and logarithmic terms relating to 23 other nodes are included in the equation, but not reported for clarity

$* * * p<0.01, * * p<0.05, * p<0.1$

These results control for the effects of population density and also for characteristics of residents that may in turn impact on land prices. One argument previously cited to account for higher values of land inside relative to outside the MUL boundary is that people value highly the rural amenity value of being on the outskirts of the city (i.e. just within the MUL). This would bid up prices for land just inside the MUL boundary, possibly creating an artificial distinction between land values on either side of the boundary. Our results indicate that this is not likely to be part of the explanation for the observed boundary effect for two reasons. First, the estimate for DMUL2 is not significantly different from zero in later years (and is negative in earlier years). Thus the distance variables are adequately capturing the values of land just inside the MUL boundary, implying that there is no extra amenity value placed on this land. Second, even if there were such higher amenity value, it is likely that higher income (and less deprived) households will move into the soughtafter area. Our extended model controls for these household characteristics and hence controls for such amenity values.

\section{Spatial Autocorrelation}

Both the baseline and extended models have been estimated with OLS. The significance tests employ standard errors that are robust to heteroskedasticity. 
However, there is still the possibility that spatial autocorrelation will be present which may bias the coefficient estimates and/or make them inefficient (Anselin, 1988).

We test for the presence of spatial autocorrelation in our estimated models using Moran's I statistic. The null hypothesis is that there is no spatial autocorrelation in the residuals. We are unable to calculate Moran's $I$ for the complete set of residuals owing to computer memory constraints given the large dataset that we are using. Instead, we test for autocorrelation (using the residuals from the full model) at the level of each TA. We employ tests at different spatial scales: up to $0.25 \mathrm{~km}$, up to $1 \mathrm{~km}$, up to $2 \mathrm{~km}$, up to $5 \mathrm{~km}$ and up to $20 \mathrm{~km}$.

The tests cover the two models (baseline and extended), each for 5 years (1992, 1995, 1998, 2001, 2003), each for seven TAs with five spatial scales: a total of 350 test statistics. Rather than presenting each of these results, we summarise the findings. We find significant spatial autocorrelation for virtually all cases over a range of $0-1,0-2 \mathrm{~km}$ and (mostly) over ranges of $0-0.25$ and $0-5 \mathrm{~km}$. We do not find spatial autocorrelation over a greater spatial range $(0-20 \mathrm{~km})$.

As a result of these tests, we estimate the same underlying relationships using the three additional techniques outlined in "Methodology", in each case for the seven TA sample in 2001 (results reported in Table 6). The most basic supplement to our approach is to retain OLS as the estimation technique, but to add dummy variables for area units. There are approximately 350 area units across the greater Auckland region compared with 8,800 meshblocks. Area units are akin to suburbs in a metropolitan area and so may capture the impact of shared amenities and desirable locations. The drawback of this approach is that if the area unit boundaries near the city outskirts are similar to the MUL boundaries, the two effects will be highly collinear and so will make it more difficult to detect the MUL boundary effect.

The estimates for the OLS area unit model again show clear, albeit more muted, MUL effects. In the baseline and extended models, the estimated ratio of DMUL2 to DMUL4 land value is 6.3 and 4.9 respectively. For reasons outlined earlier (especially the collinearity between peripheral urban area unit boundaries and the MUL boundary) these estimates are likely to be material underestimates of the MUL boundary effect.

The second approach is to estimate a spatial lag model. ${ }^{23}$ For the baseline model, the implied ratio of land values across the MUL boundary is 13.2; for the extended model, the implied ratio is 10.1 . The third approach is to estimate a spatial error model. For the baseline and extended models, the implied ratios of land within DMUL2 relative to DMUL4 are 13.2 and 10.2 respectively. Each of these estimates is similar to the estimates from the OLS model. The only estimates that give a materially different result are those that add the 350 area unit dummies to the OLS equation. These estimates almost certainly provide an under-estimate of the boundary effect. Even here, however, the effect is estimated to be in the order of a factor of 5 (extended model) or 6 (baseline model).

\footnotetext{
${ }^{23}$ Spatial lag and spatial error models have very large memory requirements and we are unable to estimate the model using all 8,000 observations. Instead we take a 50\% stratified random sample where stratification is performed on the basis of the six DMUL dummies.
} 
Table 6 Alternative model estimates (2001)

\begin{tabular}{|c|c|c|c|c|c|c|c|c|}
\hline & \multicolumn{2}{|c|}{ OLS basic model } & \multicolumn{2}{|c|}{ OLS area unit model } & \multicolumn{2}{|c|}{ Spatial lag model } & \multicolumn{2}{|c|}{ Spatial error model } \\
\hline & Baseline & Extended & Baseline & Extended & Baseline & Extended & Baseline & Extended \\
\hline $\begin{array}{l}\text { DMUL2 } \\
\text { coefficient }\end{array}$ & -0.069 & -0.032 & -0.012 & 0.000 & -0.034 & 0.044 & -0.009 & 0.060 \\
\hline $\begin{array}{l}\text { DMUL4 } \\
\text { coefficient }\end{array}$ & -2.624 & -2.380 & -1.856 & -1.594 & -2.618 & -2.268 & -2.590 & -2.261 \\
\hline Boundary ratio & 12.9 & 10.5 & 6.3 & 4.9 & 13.2 & 10.1 & 13.2 & 10.2 \\
\hline Estimate of $\rho$ & - & - & - & - & 0.349 & 0.302 & - & - \\
\hline Estimate of $\lambda$ & - & - & - & - & - & - & 0.966 & 0.956 \\
\hline
\end{tabular}

All DMUL4, $\rho$ and $\lambda$ coefficients have $p<0.01$; all DMUL2 coefficients have $p>0.1$; ' - ' $=$ not applicable

\section{Conclusions}

Land prices summarise the value that agents place on a particular location, subject to constraints on exercising their preferences. In a regional economy which is not subject to land use constraints, land will be allocated to alternative uses according to the highest private use value for that location. ${ }^{24}$ Once zoning restrictions are introduced into the analysis, certain agents may be thwarted from using particular locations for the purposes that they desire even though those purposes have the highest private land use values. In these situations, the market value of the affected land will be lower than it would be in an unregulated market, and it will instead be valued at the second (or $n$ th) best land use.

Growth limits are one form of zoning restriction. If effective, they limit the expansion of a city beyond prescribed boundaries. If they are binding, land immediately on the inward side of the boundary will be valued at a higher rate (per hectare) than land immediately on the outward side of the boundary after controlling for other factors. If the growth limits do not constitute a binding constraint, the land price gradients will not display a step change at the point of the growth limit.

Auckland formally adopted the Metropolitan Urban Limits (MUL) as a growth boundary in 1998, although these boundaries reflected earlier growth limits. Ours is the firstly publicly available study conducted to examine the effects of these growth boundaries on Auckland land prices. We face many challenges in conducting such a study. First, data must be gathered, not just on land values near the boundary, but also on values across the region so that the boundary effects can be modeled in the context of region-wide determinants of land values.

A second challenge is to specify a model that captures the highly divergent values of land across urban and rural uses in a diverse region using only a small number of parameters. The same model (but not necessarily the same parameters) should be able to capture values across a span of time exceeding a decade. Our model captures approximately $80 \%$ of the variation in land values of around 8,000 observations in

\footnotetext{
${ }^{24}$ This does not necessarily mean that the resulting land use is efficient; externalities may result in an inefficient allocation, thus forming a prima facie case for zoning decisions and other land use constraints.
} 
each year. Our estimated underlying (non-regulatory) determinants of land values across the region all accord with theoretical priors. Specifically: (1) land is highly valued near the city centre, declining (non-linearly) as distance from the CBD increases; (2) the ratio of CBD land values to outer land values has increased over time, consistent with greater agglomeration economies since the early 1990s; (3) land is generally more highly valued near other local nodes than in areas more distant from them; and (4) land is valued more highly near the coast than in areas distant from coastal locations.

The third challenge is to adopt methods that capture the impact of the MUL boundary on land prices. We do so by incorporating six variables that identify land which is: (1) well inside the MUL boundary,(2) just within the boundary, (3) sitting astride the boundary, (4) sitting just outside the boundary, (5) sitting just beyond the previous areas of land, and (6) sitting well beyond the boundary. For our model of regional land values to be considered adequate, we require the second category of land (i.e. land just within the boundary) to be modeled systematically by the model in the same manner as land well within the boundary (at least where the land is being used principally for urban purposes). Our model meets this challenge, especially in later years when the growth limit is increasingly binding.

Fourth, we subject the model to different specifications that capture the possibility that land values reflect the characteristics of the people living within each area as well as more general location characteristics. Inclusion of such variables may impart a downward bias to the boundary effect estimate if people's location patterns are influenced directly by the growth limit and/or by the price effects of the growth limit. By contrast, their omission could bias the boundary effects upwards if there is a significant omitted variable problem caused, for instance, by presence of rural amenity values correlated with the characteristics of people living in these locations. We estimate a baseline model that excludes such effects and an extended model that includes three such variables. Our findings are robust to inclusion or exclusion of these 'social' variables.

Finally, we test whether the estimated parameters are robust to alternative ways of modeling the spatial patterns in the data. Our baseline and extended models are initially estimated using OLS with no explicit regard to the spatial pattern of residuals (other than the inclusion of 24 local nodes for areas that may be expected to have high localized land prices). These estimates display significant spatial autocorrelation. When we re-estimate the models explicitly as a spatial lag model, there is almost no change in the parameters of interest (i.e. the boundary effect). Similarly, when we re-estimate the models as a spatial error model, the parameters remain stable.

The only case where we find a material difference in parameter estimates is where we soak up spatial autocorrelation through the inclusion of 350 area unit dummies in addition to the other variables in the model. The problem with this approach is that the area unit boundaries near the growth limit may be (exactly or approximately) contiguous with the MUL boundaries, in which case the latter will not have explanatory power for the relevant areas over and above the area unit effect.

As expected, the inclusion of area unit effects reduces the estimated boundary impact. For these models, the estimated boundary effect is approximately 5 to 6 in 2001. It is conceivable that the area unit dummies are capturing some amenity 
effects that are not captured adequately by our other models. However, the estimated boundary effects in the area unit model almost certainly represent an under-statement of the actual boundary effect for reasons outlined above.

All other estimates find a boundary land value ratio of between 7.9 and 13.2, with the lower estimates coming earlier in the sample period when the growth boundary is less likely to have been a binding constraint. These estimates variously control for distance effects (from the CBD, local nodes and the coast), TA effects (reflecting different amenities and property taxes by local authority), rural land-use, social and population factors, spatial lags and spatial errors.

The data indicate that the largest relative land price increases between 1992 and 2003 have occurred for land located just outside the urban boundary. This could reflect increasing amenity value being placed on this land or an increasing option value being placed on this land for future development. With overall Auckland land values rising by almost $60 \%$ relative to land values in other North Island cities over these twelve years, relaxation of the growth limit (consistent with optimal inventory policy posited by Knaap and Hopkins 2001) is a reasonable conjecture on the part of land owners and property investors. Some small relaxations in the boundary have occurred in recent years, but too recent for us to be able to model their impacts. Future research will be able to examine what impacts these specific relaxations have had on local land prices.

The rise in land values in Auckland relative to other North Island cities over our study period (1992-2004), and the strengthening in the boundary effect, has implications for the operation of the city's growth limits. Our results are consistent with US findings that binding planning restrictions can result in raised property prices. By itself, this finding does not discredit the use of an MUL as part of an optimal planning regime. The existence of unpriced externalities arising from unconstrained city expansion may create a role for such a growth limit. However the work of Knaap and Hopkins (2001) indicates that a growth limit should not be conceived as a static boundary; price effects arising from an increasingly binding constraint provide information that can be used to update the location of the boundary over time.

Furthermore, the insights of Anas and Rhee (2007) suggest that growth limits need to reflect the actual characteristics of the city rather than an idealized monocentric city model. Auckland is a polycentric city with a population that grew, on average, by $2.2 \%$ between 1991 and 2006 (census years), a 38\% increase. Simple application of growth limits, with long periods between boundary reviews could, under these circumstances result in considerable inefficiencies and inequities, including problems of housing affordability (Grimes et al. 2007). Our results therefore imply that growth limits within Auckland should be reviewed in a flexible manner that accounts for the impacts of an increasingly binding constraint.

Acknowledgements This research was undertaken as part of Motu's FRST-funded programme on Infrastructure (FRST grant MOTU0601). We thank FRST for its support and Quotable Value New Zealand for provision of rateable value information. We also thank our colleagues at Motu and University of Waikato, plus Kathryn Bicknell and other participants at the New Zealand Association of Economists conference (Christchurch, June 2007) and referees of this journal for valuable comments. However we remain solely responsible for the analysis and for the views expressed. 
Open Access This article is distributed under the terms of the Creative Commons Attribution Noncommercial License which permits any noncommercial use, distribution, and reproduction in any medium, provided the original author(s) and source are credited.

\section{References}

Anas, A., \& Hyok-Joo, R. (2006). Curbing excess sprawl with congestion tolls and urban boundaries. Regional Science and Urban Economics, 36, 510-541.

Anas, A., \& Hyok-Joo, R. (2007). When are urban growth boundaries not second-best policies to congestion tolls? Journal of Urban Economics, 61, 263-286.

Arnott, R. (1979). Unpriced transport congestion. Journal of Economic Theory, 21, 294-316.

Anselin, L. (1988). Spatial econometrics: Methods and models. Dordrecht: Kluwer.

Anthony, J. (2003). The effects of Florida's growth management act on housing affordability. Journal of the American Planning Association, 69, 282-295.

Auckland Regional Growth Forum (1999). Metropolitan urban limits: Impact on land prices. Auckland: ARGS.

Bourassa, S., Martin, H., \& Jian, S. (2006). The price of aesthetic externalities. The Appraisal Journal, 74 (1), 14-29.

Crampton, P., Salmond, R. C. E., Kirkpatrick, R. S., \& Skelly, C. (2000). Degrees of deprivation in New Zealand: An atlas of socioeconomic difference. Albany: David Bateman.

Dowall, D. E. (1979). The effect of land use and environmental regulations on housing costs. Policy Studies Journal, 8, 277-288.

Dowall, D. E., \& Landis, J. (1982). Land use controls and housing costs: An examination of the San Francisco Bay area communities. Journal of the American Real Estate and Urban Economics Association, 10, 67-93.

Downs, A. (1992). Regulatory barriers to affordable housing. Journal of the American Planning Association, 58, 419-421.

DTZ (2007). Housing supply in the Auckland Region 2000-2005: Auckland Region District plan review. Wellington: Motu Economic and Public Policy Research.

Glaeser, E., \& Gyourko, J. (2002). The impact of zoning on housing affordability. HIER Discussion Paper 1948, Cambridge, MA: Harvard Institute of Economic Research.

Glaeser, E., Gyourko, J. (2003). The impact of building restrictions on housing affordability. FRBNY Economic Policy Review, June, pp. 21-29.

Glaeser, E., Gyourko, J., \& Saks, R. (2005). Why is Manhattan so expensive? Regulation and the rise in housing prices. Journal of Law and Economics, 48(2), 331-369.

Glaeser, E., \& Ward, B. A. (2006). The causes and consequences of land use regulation: Evidence from Greater Boston, NBER Working Paper 12601.

Grimes, A., Aitken, A., Mitchell, I., \& Smith, V. (2007). Housing supply in the Auckland Region 20002005. Wellington: Centre for Housing Research Aotearoa New Zealand. http://www.hnzc.co.nz/chr/ pdfs/housing-supply-in-the-auckland-region-2000-2005.pdf.

Grimes, A., \& Liang, Y. (2007). An Auckland land value annual database. Motu Working Paper 07-04. Wellington: Motu Economic \& Public Policy Research Trust.

Gyourko, J., Mayer, C., \& Sinai, T. (2006) Superstar cities. NBER Working Paper 12355, National Bureau of Economic Research.

Haughwout, A. (2002). Public infrastructure investments, productivity and welfare in fixed geographic areas. Journal of Public Economics, 83(3), 405-428.

Haurin, D., Dietz, R., \& Weinberg, B. (2003). The impact of neighborhood homeownership rates: A review of the theoretical and empirical literature. Journal of Housing Research, 13(2), 119-151.

Kanemoto, Y. (1977). Cost-benefit analysis and the second-best land use for transportation. Journal of Urban Economics, 4, 483-503.

Katz, L., \& Rosen, K. T. (1987). The interjurisdictional effects of growth controls on housing prices. Journal of Law and Economics, 30, 149-160.

Knaap, G. J., \& Hopkins, L. D. (2001). The inventory approach to urban growth boundaries. Journal of the American Planning Association, 67(3), 314-326.

Landis, J. (1986). Land regulation and the price of new housing: Lessons from three Californian cities. Journal of the American Planning Association, 52, 9-21. 
Malpezzi, S. (1996). Housing prices, externalities, and regulation in U.S. Metropolitan areas. Journal of Housing Research, 7(2), 209-241.

McMillen, D., \& McDonald, J. (2004). Reaction of house prices to a new rapid transit line: Chicago's midway line, 1983-1999. Real Estate Economics, 32, 463-486.

Moran, P. (1950). Notes on continuous stochastic phenomena. Biometrika, 37, 17-33.

Pendall, R. (1999). Do land use controls cause sprawl? Environment and Planning B: Planning and Design, 26, 555-571.

Pendall, R., Puentes, R., \& Martin, J. (2006). From traditional to reformed: A review of the land use regulations in the nation's 50 largest metropolitan areas. Research Brief, The Brookings Institution, August.

Pines, D., \& Sadka, E. (1985). Zoning, first-best, second-best and third-best criteria for allocating land to roads. Journal of Urban Economics, 17, 167-183.

Roback, J. (1982). Wages, rents and the quality of life. Journal of Political Economy, 90, 1257-1278.

Ryan, C. M., Wilson, J. P., \& Fulton, W. (2004). Living on the edge: Growth policy choices for Ventura county and Southern California. In J. R. Wolch, M. Pastor, \& P. Dreier (Eds.), Regional futures: Public policy and the making of 21 st century Los Angeles. Minneapolis: University of Minnesota Press.

Samarshinghe, O. E., \& Sharp, B. M. H. (2007). Analysing spatial effects in hedonic house price models. Draft mimeo, University of Auckland.

Schwartz, S., Hansen, D., \& Green, R. (1981). Suburban growth controls and the price of new housing. Journal of Environmental Economics and Management, 8, 303-320.

Zorn, P., Hansen, D., \& Schwartz, S. I. (1986). Mitigating the price effects of growth control regulations: A case study of Davis, California. Land Economics, 62, 46-57. 